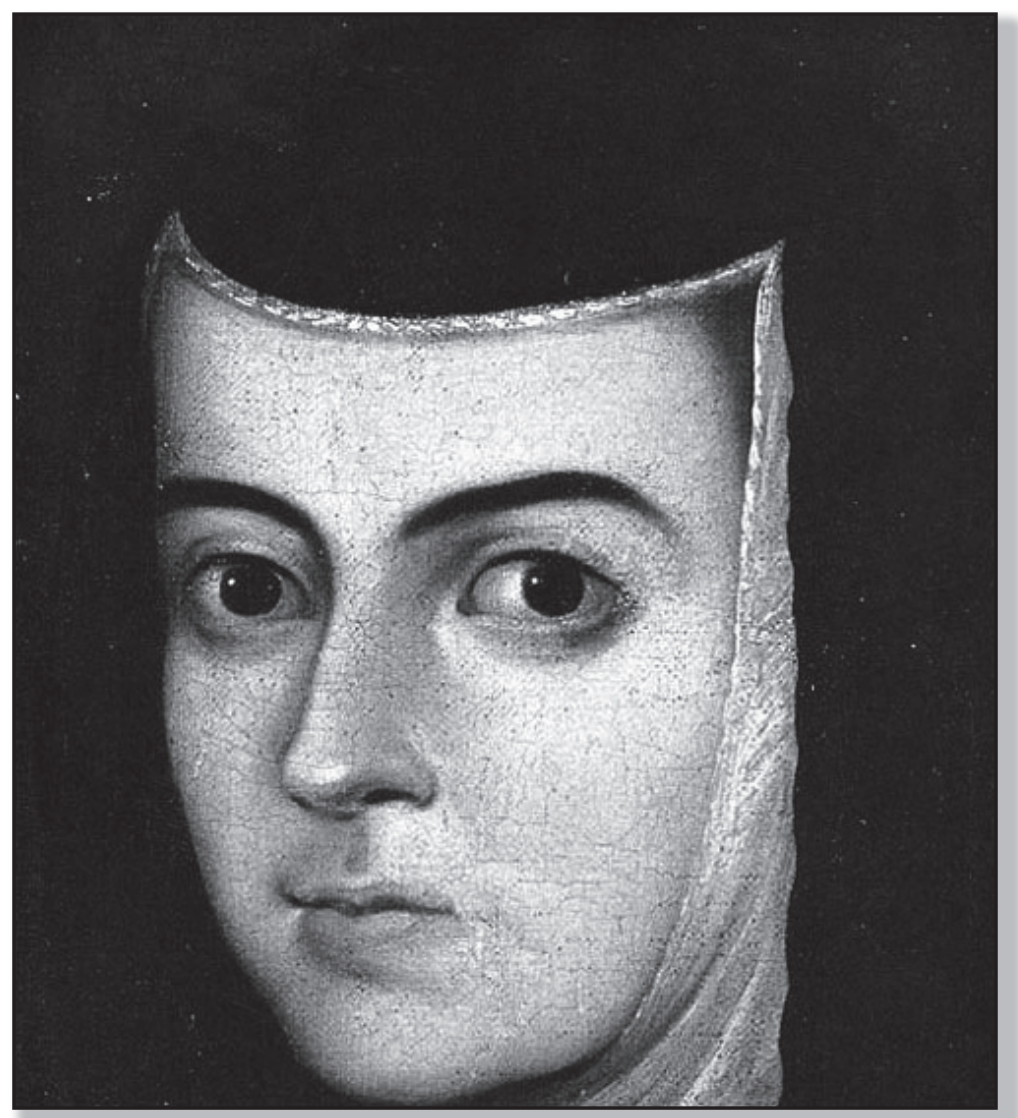

Detalle de la cara de Sor Juana Inés de la Cruz. Juan Miranda, siglo XVIII. Tomada de: http:/www.cervantesvirtual.com/portales/sor_juana_ines_de_la_cruz/ imagenes_sor_juana/imagen/imagenes_sor_juana_07_sorjuana/ 


\title{
Sobre lo divino, la religión y la mujer en Bacon
}

\section{About the divine, religion and women in Bacon}

\author{
Diana Solano Villareal \\ Escuela de Filosofía \\ Universidad Nacional, Costa Rica \\ 1.solano.villareal@una.cr
}

\begin{abstract}
Resumen
Este artículo versa sobre los temas de lo divino, la religión y la mujer, en las obras de Bacon: El Avance del Aprendizaje, Preparación hacia una Historia Natural y Experimental, Valerius terminus: o de la Interpretación de la Naturaleza y Dignitate et Augmentis Scientiarum, en nuestros días. Lo anterior desde la teoría del grupo Modernidad/Colonialidad, en los estudios decoloniales y la teoría feminista general.
\end{abstract}

Palabras claves: mujeres, religión, dominio, Francis Bacon

\begin{abstract}
Abstret
This article deals with the themes of the divine, religion and women, in the Bacon's books: The Advance of Learning, Preparation towards a Natural and Experimental History, Valerius terminus: Or the Interpretation of Nature and Dignitate et Augmentis Scientiarum, in our days. The above from the theory of the group Modernity / Coloniality, in colonial studies and general feminist theory.
\end{abstract}

Keywords: women, religion, domain, Francis Bacon 


\section{Introducción}

$\mathbf{E}$ ste artículo estudia la posición de Bacon respecto del Otro en los libros El Avance del Aprendizaje, Preparación hacia una Historia Natural y Experimental, Valerius terminus: o de la Interpretación de la Naturaleza y Dignitate et Augmentis Scientiarum. Aquí se explica cuáles son, a mi entender, las características de la negación del Otro de Francis Bacon.

La perspectiva teórica desde la cual realizaré la investigación propuesta es la que corresponde a la teoría del Grupo Modernidad/ Colonialidad. Ahora bien, ¿cómo se relaciona la teoría del Grupo Modernidad/ Colonialidad con los escritos de Francis Bacon? Pienso que en los planteamientos epistemológicos baconianos se deja muy claro que el método que allí se expone no es para todos, y de ello podemos inferir que no todos están calificados para tener acceso a la verdad. El Dr. Bernal Herrera nos dice en su teoría de la Modernidad Bipolar (la cual se utilizará como apoyo para este trabajo), que en el polo metropolitano se dieron procesos liberadores basados en el conocimiento, los cuales no siempre fueron totales o completos, $\mathrm{y}$ en el polo colonial menos aún, pues no fueron pensados para ellos (Herrera, 2007: 20).

Francis Bacon es el más famoso y beligerante promotor de las ideas provenientes del Renacimiento, quien además creía firmemente que el conocimiento obtenido mediante el método correcto (su método inductivo) podía generar grandes beneficios al mundo. La naturaleza, ente misterioso y temido por el ser humano desde su aparición en el planeta, se podía estudiar, comprender y sistematizar realizando experimentos y extrayendo conclusiones a partir de las evidencias obtenidas siguiendo el ya mencionado método inductivo. Bacon alegaba que, con un grupo de ingenios bien adiestrados, la investigación inductiva conduciría a la verdad, pero: ¿Cuáles pueden ser estos ingenios? ¿Podemos partir de cualquier mente? $\mathrm{O} ¿$ Hay requisitos previos? ¿Cuáles podrían ser estos? ¿Serán estos requisitos más políticos que epistémicos?

Uno de los mitos más ampliamente aceptados de modernidad es que esta última se desarrolló prácticamente al margen de la religión y, si se quiere, de la divinidad. No obstante, esto no es cierto como ya hemos dicho; es un mito que quizás se deba a algunos movimientos modernos (especialmente políticos) que se declararon anticlericales e incluso rayaron en el ateísmo'.

Lo cierto del caso es que las creencias religiosas desde los propios inicios de la Modernidad (1492 según el grupo Modernidad/ Colonialidad) ya sean católicos o protestantes (con todas sus variantes) jugaron un papel crítico en el surgimiento y consolidación de la Modernidad en Europa y sus colonias.

Francis Bacon, a quien se ha llamado uno de los padres de la Modernidad, no era de hecho ningún ateo. Fue, como es esperable, dada la época y el lugar en que vivió, un inglés anglicano. Y es que realmente no tenía muchas opciones pues contrario a lo que

1 Uno de los casos más conocidos y paradigmáticos es el de La Revolución Francesa cuyos dirigentes eran abiertamente anticlericales. En su momento Robespierre (llamado el incorruptible con buena razón) se vio afectado por el exceso de poder que obstentaba y en su delirio cambió el culto al dios judeo-cristiano por el culto a la Razón. 
se cree, la Iglesia Anglicana no era un bastión de libertad y tolerancia ${ }^{2}$, cosa fácil de entender si tenemos en cuenta que el monarca no solo era (y sigue siendo) tal, sino también cabeza de la Iglesia ${ }^{3}$. Así las cosas, encontrarse disconforme con la doctrina de la Iglesia era prácticamente un acto de traición. Pensar y escribir sobre cuestiones teológicas en la Inglaterra de Bacon era una cuestión de cuidado. No es que se tuviera sobre su cuello la amenaza de la Inquisición como en España, Italia e incluso en Portugal, empero, siempre era mejor pensar muy bien lo que se fuera a escribir.

Ahora bien, dado que la filosofía de Bacon fue fundamentalmente, aunque no únicamente, sobre la epistemología, se podría pensar que el filósofo inglés no se refirió de modo alguno a cuestiones religiosas, pero sí que lo hizo. Debía hacerlo pues los menesteres del conocimiento también tocan el reino de las creencias religiosas.

\section{El conocimiento de lo divino y el conocimiento del mundo}

Como es bien sabido, dos de las principales preguntas que la epistemología intenta contestar son: ¿qué podemos conocer? y ¿hasta dónde podemos conocer? Por ello las ya viejas cuestiones sobre lo que podemos conocer y lo que no, no podrían faltar en el pensamiento de Bacon.

El conocimiento de lo divino, de aquello que está más allá de los sentidos, de lo

2 Para más información a este respecto se puede consultar cualquier historia (seria) de Inglaterra específicamente en los reinados de Enrique VIII (1509- 1549), de María Tudor (1553- 1558).

3 Por encima de los obispos de Canterbury y Saint Paul, los más altos en la jerarquía de la Iglesia Anglicana. metafísico en el sentido más puro, siempre ha provocado grandes discusiones. El mundo de lo divino en lo que hoy conocemos como Europa, desde los propios inicios de la cristianización del Imperio Romano, ha sido un asunto espinoso especialmente después del Concilio de Nicea (325 d.C) y de la instauración de Constantino el Grande del Credo Nicénico.

El Barón de Verulam en Valerius or the Interpretation or Nature invierte varias páginas para contestar una pregunta muy complicada, muy discutida y cuyos intentos de respuesta podrían suscitar no solo muchas más preguntas, sino un completo cambio de conciencia en los cristianos que tanto la Iglesia Anglicana como la Católica Romana no recibirían de la mejor manera. La pregunta a la que nos referimos es: ¿fue el deseo de conocimiento lo que hemos llamado pecado original? Desde luego este cuestionamiento supone otros tales como ¿qué conocimiento quería el ser humano? ¿para qué lo quería?

Posiblemente más que las anteriores preguntas, la que aparezca en la mente de muchos de los amables lectores sea: ¿el Pecado Original no fue el coito entre Adán y Eva? Bien, esta fue la solución que Agustín, Obispo de Hipona, dio al problema que él mismo se inventó. Sin embargo, a los anglicanos no les satisfacía la solución de un santo católico, máxime en un momento en el que los clérigos de Inglaterra habían podido acceder al matrimonio después de cientos de años ${ }^{4}$ de que les fuera vedado.

4 La historia del celibato en la Iglesia Católica Romana es larga y compleja, pero haciendo un esfuerzo en resumir, podemos decir que fue con el Papa Inocencio II en el segundo Concilio de Letrán (1139) en donde se reafirma lo establecido a este respecto en el anterior concilio (primer Concilio de Letrán, 1123). 
Volviendo al tema del conocimiento y del pecado original, nos encontramos con un gran problema si partimos del hecho de que para los creyentes cristianos el pecado original es el inicio de todo el mal en el mundo humano y causa de su caí$\mathrm{da}$, entonces tenemos ante nosotros un asunto de proporciones bíblicas. Que el pecado original se correspondiera con la sexualidad humana era un asunto del que la Iglesia Católica, además, había sacado muchísimo provecho. Había encontrado en una parte inherente a la naturaleza del ser humano tierra fértil para sembrar la culpabilidad y a partir de ella un dominio perverso si se quiere, pero muy efectivo.

Los anglicanos se preguntaban, si el pecado original no es el sexo ¿entonces qué será? ¿el conocimiento? Al final de cuentas, según el Génesis, existían dos árboles prohibidos en el Jardín del Edén: el del bien y del mal del cual comieron Adán y Eva y el del conocimiento del cual Dios les apartó rápidamente. La cuestión estaba en la palestra: ¿era la búsqueda de conocimiento maligna en sí misma? ¿deberíamos permanecer mansamente en la ignorancia? ¿es esa la voluntad de Dios? ¿la curiosidad en sí será entonces condenable? ¿por qué no? Si la sexualidad humana se consideró el primer pecado, con el que nacemos manchados, ¿por qué no la curiosidad y el impulso hacia el conocimiento tan natural en el ser humano? El tema del conocimiento y la ignorancia ya se había discutido desde siglos atrás. El mejor ejemplo lo constituye la obra capital de Nicolás de Cusa: De Docta Ignorantia 5 (1440). Los

5 En este libro (a grandísimos rasgos) se propone que el conocimiento proviene de los sentidos, pero no es tal y por ello el verdadero conocimiento no puede planteamientos de Cusa no fueron del total agrado de algunos anglicanos, entre ellos Francis Bacon.

En la ya mencionada Valerius Terminus, el Conde de Saint Albans nos explica por qué, a su juicio, el deseo de conocer de los hombres (no en sentido genérico sino de humanos Xy) no puede ser causa de su caída. Por lo menos no per se. El ¿para qué? es lo que determina si el afán por conseguir el saber es causa de pecado o no.

El ser humano peca cuando quiere ser como Dios y encontrar en el conocimiento la forma (muy a su conveniencia) de establecer el bien y el mal. Dicho de otra forma, si el ser humano desea conocer para mejorar su vida material, para desentrañar los secretos de la naturaleza, entonces no hay ningún problema. En palabras del mismo Bacon en The Great Instauration: To ... which gave occasion to the fall, but it was an aspiring desire to attain to that part of moral knowledge which define... of good and evil... ${ }^{6}$ (Bacon, 2014, p. 221).

Cuando el individuo humano pretende hacerse con la prerrogativa de establecer el bien y el mal, está en serios problemas pues esta normativa ya existe (y es vinculante para todo ser humano, vivo o muerto, en cualquier parte). La verdadera transgresión en el Jardín del Edén fue desear el conocimiento, pero para ser como Dios,

provenir de fuera del ser humano, sino necesariamente de adentro. Es decir, el conocimiento está dentro de cada individuo. Talvez esté de más decir que esta propuesta está en franca oposición con la futura actitud hacia el conocimiento (por lo menos el científico) en la Modernidad.

$6 \quad$... a los que tienen ocasión de fracasar, pero era un fuerte deseo de alcanzar esa parte del conocimiento moral que definía el bien y el mal... 
... whereby to dispute God's commandments and not to depend upon the revelation of his will, which was the original temptation$^{7}$ (Bacon, 2014, p. 221).

La distinción entre el bien y el mal no se puede ni se debe buscar en ningún lugar más que en la Revelación. Para Bacon, la religión (judeo- cristiana anglicana) es la única y verdadera fuente de moralidad, y no hace falta demasiada astucia para darse cuenta de las terribles consecuencias que esto acarrea, no solo para las sociedades europeas, sino también para las sociedades que para el siglo XVI ya habían comenzado a conquistar y para las que próximamente conquistarían en América, Asia y África.

\section{La religión de los pueblos no europeos}

En la Europa de Bacon, ya había comenzado a arder Troya con la Reforma Protestante. Antes incluso del nacimiento de este y con la llegada de los españoles a América, aparece inmediatamente la condena respecto a la falta de moralidad de los autóctonos americanos en tanto no poseían ninguna religión conocida. Entonces como católicos inician el ampliamente conocido proceso de cristianización católica. Los habitantes originarios de América debían dejar de ser ignorantes de la única y verdadera Revelación pues con ella adquirirían moralidad. Ahora sabemos que los autóctonos americanos y los del resto del mundo poseían moralidad y también religión, pero en la mentalidad cerrada y fundamentalista de los europeos del siglo

$7 \quad$... con lo que disputar los mandamientos de Dios y no depender de la revelación de su voluntad, que fue la tentación original.
XV no cabía más posibilidad de una moral religiosa cristiana.

La Modernidad es profundamente moralista y también expansionista. El hecho que uno de los denominados Padre de la Modernidad establezca en sus reflexiones que la moralidad solo pueda provenir de la Revelación (traducida e interpretada claro por las diferentes iglesias cristianas europeas) cristiana, nos deja clara una de las fuentes filosóficas en las que la intolerancia religiosa se justificó.

Hacemos hincapié en la palabra filosófica en cuanto la teología cristiana (también absolutamente teñida de intolerancia) se encargó, prácticamente desde que los españoles pisaron el Caribe, de justificar la imposición del catolicismo a los habitantes de los nuevos territorios "descubiertos.. Y si es verdad que los conquistadores españoles y portugueses no prestarían mayor atención a Bacon (de hecho, la gran mayoría de ellos era analfabeta), también es verdad que a los exploradores y colonizadores ingleses les serían de gran utilidad, pues los superiores de sus superiores pudieron estar expuestos a la reflexión filosófica baconiana.

\section{La colonización inglesa de América del Norte: actuales Estados Unidos de América y Canadá}

Cuando los ingleses llegaron a la costa este de lo que hoy conocemos como Estados Unidos y se encontraron con sus pobladores, solo vieron en ellos a un grupo de individuos semejantes a humanos que vivían como poco menos que animales 
no humanos ${ }^{8}$. Los autóctonos fueron considerados grupos que carecían de moral, por lo cual (entre otros muchos prejuicios) no se les respetó.

En el momento de la colonización de la costa este de Norteamérica, la imagen que los ingleses tenían de los pueblos originarios no había cambiado; de hecho se había endurecido y, a diferencia de los españoles y portugueses (para bien y para mal), no establecieron relaciones de mestizaje. Una de las razones que explica esto es justamente la religión de los colonizadores ingleses que al viajar con sus familias tendrían sobre sus conciencias, de una forma recalcitrante, los mandamientos de no fornicar y de no cometer adulterio y menos con criaturas (a las que ellos consideraban) semejantes a humanos, sin estar seguros de que lo fueran. El término con el que se les designó, puritanos, no era gratuito. Para los puritanos, seguir los mandamientos de la forma más ortodoxa y pura era la base de sus creencias y la razón por la que dejaron Inglaterra.

No obstante, el hecho de que los pobladores originarios de América fueran considerados inmorales y casi animales no humanos (lo cual no justifica el trato cruel, pues también son seres sintientes), pesó mucho. No conocían la revelación del dios de los cristianos, luego no tenían noción de lo bueno y de lo malo; es más, se les consideraba, para muchos efectos, idólatras y

8 Este concepto es acuñado por Peter Singer en 1975. Por otra parte, es oportuno recordar que en la mayoría del Viejo Mundo los animales no humanos eran vistos como brutos de los cuales se podía disponer sin ningún reparo. Hoy, afortunadamente y gracias a ciencias guiadas por la ética aplicada a la vida, esa odiosa posición está cambiando. perversos, con los cuales era mejor tener el menor contacto posible.

Las organizaciones sociales y religiosas de los autóctonos no fueron (y para muchas personas, siguen sin ser) aceptadas como tales, entonces no eran en un sentido estricto seres humanos, por lo menos no civilizados. La palabra civilizados no se utilizaba en esa época, empero, el sentido de un grupo de humanos con organizaciones sociales, político económicas y religiosas legítimas (europeas) subyacía en la mentalidad de los colonizadores ingleses.

La carencia de organizaciones sociales válidas, hacían de los Sioux, Pies Negros, Apaches, Cherokees, Hopies y Navajos, entre muchos más, seres más cercanos a la naturaleza, o sea, menos de la civilización, la cual por definición está justamente alejada o divorciada de lo natural, excepto para sacarle el mayor provecho posible mediante el dominio sin ninguna consideración ética o moral.

La dicotomía naturaleza civilización, o mejor, cultura se estaba consolidando como tal y en los inicios de la Modernidad (y tristemente hasta la fecha, en la mentalidad de los recién nacidos occidentales y occidentalizados), la primera se perfilaba como la gran perdedora, pues en la otra dicotomía naciente, sujeto objeto (esta evidentemente epistemológica) el sujeto será la cultura y el objeto la natura.

Para desdicha de los pueblos originarios de América, sus conquistadores europeos consideraban que solo ellos poseían lo que más adelante se conocería como cultura y, por lo tanto, todos los demás pueblos del 
mundo carecerían de la principal característica que les otorgaría la jerarquía de humanos merecedores de consideraciones morales, de dignidad y respeto.

En este punto, es muy importante detenernos brevemente en el concepto de cultura y su relación con las religiones. La cultura como concepto es muy problemática, pues el debate respecto a qué es y qué implica, es muy basto, intenso y sin vistas de pronta solución ${ }^{9}$. Por ello nos limitaremos a señalar un punto en que prácticamente todos los estudiosos están de acuerdo y es que la religión es parte de la cultura y la cultura de la religión. Una influye en la otra de maneras muchas veces sorprendente. Hoy sabemos (y esto también es aceptado por casi todos los estudiosos del tema: antropólogos, sociólogos, etnógrafos, etc.) que solo los humanos producimos cultura, el resto de los animales al parecer no. En otras palabras, el único requisito para producir cultura es ser humano en sociedad con otros humanos.

Ahora bien, siguiendo con el tema de las religiones, debemos decir que el asunto crítico con ellas es que estas dotan de significado a la vida e intentan dar respuesta a algunas de las preguntas más agudas de los individuos y los pueblos: ¿por qué estamos aquí? ¿cuál es el sentido de la vida? ¿qué se supone que debo hacer en el mundo que me correspondió vivir? ¿qué es lo bueno y qué lo malo? Cada cultura mediante sus creencias religiosas contesta (muy a su manera) las preguntas antes planteadas.

9 Los propósitos de este trabajo tampoco nos permiten dedicar el espacio necesario para siquiera esbozar las posiciones más relevantes.
Si Bacon tiene razón y la única forma de contestar los cuestionamientos sobre cómo debe vivir el ser humano es por medio de la revelación del dios Judeo- cristiano, los pueblos no europeos carecerían de las reglas básicas de la convivencia civilizada, con lo que se erguiría ante los conquistadores una pregunta cuya respuesta definirá el mundo hasta nuestros días: ¿deberíamos enseñarle a estos seres con apariencia humana las verdaderas creencias espirituales? La respuesta de los católicos fue un inmediato sí, mientras la de los puritanos fue un inmediato no, y simplemente se limitaron a mantenerse lejos. Años más tarde, después de la independencia de las Trece Colonias, la tónica fue arrebatar sus tierras a los pueblos originarios de la forma que fuera necesaria, muchas veces con una sádica violencia.

Las creencias religiosas definen profunda, aunque no únicamente, a los pueblos. Cada cual vivirá de acuerdo con lo que consideren bueno. Es un asunto bien sabido que las cuestiones morales son muy diversas y hasta contradictorias entre una cultura y otra. No obstante, en un plano puramente teórico, todas persiguen el bien y la justicia; el gran bemol es cuando llegamos a la práctica, pues existen demasiados factores que influyen en cómo se conciben los conceptos de bien y justicia (por mencionar solo dos), desde factores físicos (clima y topografía, por ejemplo) hasta históricos.

Que una religión considere que es la única y verdadera no debería ser mayor problema, pero lo es cuando aparte es intolerante con otras creencias y expansiva como lo es el cristianismo. Y eso no es todo, el panorama empeora al ser la referencia 
espiritual de los conquistadores y colonizadores de un territorio habitado previamente por otras personas.

Estas terribles características de los imperios cristianos han derramado ríos de sangre durante milenios. Ni siquiera los brutales romanos paganos impusieron sus creencias religiosas ${ }^{10}$. Es verdad que el culto al emperador se expandió por todo el imperio pero jamás demandaron de las personas lo que los posteriores romanos cristianos llegaron a demandar después del edicto de Tesalónica del año 380 d.C. por el cual el emperador Teodosio convirtió el cristianismo en religión oficial (y obligatoria) del Imperio Romano. Con este edicto, los perseguidos serán los no cristianos:

Cunctos populos, quo clementiae nostrae regit temperamentum, intali volumus religione versari, quam divinum Petrum apostolum tradidisse Romanis religio us quo ad nuc ab ipso insinuata declarat quamque pontificem Damasum sequi claret et Petrum Aleksandricie episcopum vivum apostolicae sanctitatis, hoc est, ut secundum apostolicam disciplinam evangelicam quo doctrinam patris et filii et spiritum sancti unam deitatem subparili maiestate et sub pia trinitate credamus. Hane legem secuentes christianorum catholicorum nomen iubemus

10 Existe la creencia de que el Imperio Romano persiguió implacable y sistemáticamente a los primeros cristianos, pero no es verdad. En realidad las persecuciones a los cristianos, solo por serlo, se dieron en dos momentos, con Nerón luego del gran incendio de Roma en el 66 d.C. y durante el reinado de Diocleciano. Fuera de estos dos momentos, los cristianos vivieron en paz pues su fe no era ilegal. Prueba de lo anterior es que en el año 112 d.C. Plinio el joven, gobernador de Bitinia en la actual Turquía, le escribió al emperador Trajano una carta con el tema de cómo manejar a los cristianos. Trajano fue muy claro al respecto, mientras no contravinieran la ley no debían ser molestados. Esta política se mantuvo como tal hasta Diocleciano. amplecti, relicuos vero dementes vesanos quo ivdicantes haeretici dogmatis infamian sustinere " nec conciliabula eorum eclessierum noman accipere "divina prinun vindicta, post etiam motus nostri, quem exsaelesti arbitro sumpserimus, ultione plectendos. (Código teodosiano 16.1.2. C. Th 16.1.2) ${ }^{11}$

Esta es la forma de actuar que los cristianos consideraron, muy a su beneplácito, legítima. Francis Bacon como cristiano anglicano, si bien consideraba el actuar de la Iglesia Católica con respecto a otros credos cristianos, inaceptable, pensaría que su fe sería la única y verdadera, fuente de moralidad y orden, por lo tanto, muy lógicamente, las demás creencias serán falsas y debían ser toleradas.

La Modernidad se ha vendido como tolerante, pero ciertamente no lo es. No puede respetar lo más sagrado que tiene un ser humano: sus creencias. No estamos diciendo que las creencias espirituales no deban ser discutidas, debatidas nunca, pues se crearían tabúes (más de los que ya existen) y esa no es la intención. Las

11 Queremos que todos los pueblos que son gobernados por la administración de nuestra clemencia profesen, la religión que el divino apóstol Pedro dio a los romanos, que hasta hoy se ha predicado como la predicó el mismo, y que es evidente que profesen el pontífice Damaso y el obispo de Alejandría. Pedro, hombre de santidad apostólica. Esto es, según la doctrina apostólica y la doctrina evangélica, creemos en la divinidad única del Padre, del Hijo y del Espíritu Santo bajo el concepto de igual majestad y la piadosa Trinidad. Ordenamos que tengan el nombre de cristianos católicos. Quienes sigan esta norma, mientras que los demás los juzgamos de dementes y locos sobre los que pesará la infamia de la herejía, sus lugares de reunión no recibirán el nombre de iglesias y serán objeto primero de la venganza divina, y después serán castigados por nuestra propia iniciativa que adoptaremos siguiendo la voluntad celestial. En: http://penelope.uchicago. edu/Thayer/E/Roman/Texts/secondary/SMIGRA*/ Codex_Theodosianus.html 
creencias religiosas deben discutirse, analizarse y evaluarse pero con muchísimo respeto y apertura de mente. Ha sido solo recientemente que se ha dado cierta apertura por parte de personas de mente más abierta para la discusión y evaluación de sus creencias religiosas, y también para el conocimiento más objetivo de otros credos religiosos.

Lo cierto es que Bacon ha influido mucho en el pensamiento moderno de los pueblos occidentales, especialmente los angloparlantes, y sobre su accionar respecto al trato con otros pueblos a los cuales conquistaron. La negativa de Bacon de conceder fuente de moral a ningún conocimiento que no proviniera de la revelación judeocristiana y la posterior afirmación de Inmanuel Kant de que los pueblos que no se habían modernizado (lo que implicaba cristianizarse) permanecerían en la minoría de edad (es decir, no eran capaces de autodeterminarse como grupos, como pueblos) y debía sentir por ellos la menor simpatía pues estos pueblos no modernos eran culpables de no serlo. Una posición tan amarga como la anterior daría una amarga guía a las colonizaciones europeas.

Empero, el asunto religioso no acaba aquí. Sabemos que los europeos no solo eran religiosos fanáticos e intolerantes, también eran lo que hoy llamaríamos misóginos, lo que representó un problema más para los europeos (ingleses en este caso) pues en muchas cuestiones religiosas y espirituales de los autóctonos americanos, las mujeres ocupaban importantes puestos, tales como chamanas (lugar que hasta el día de hoy siguen ocupando las mujeres mapuches en su cultura). Es verdad que las mujeres tienen un papel para interpretar dentro de la institucional de la Iglesia Católica: pueden ser monjas, por ejemplo, y llegar a puestos como abadesas; no obstante, siempre estarán sometidas por principio (en alguna medida, más o menos, dependiendo de la situación) a la autoridad masculina.

En cambio, para muchas religiones americanas precolombinas, la presencia de mujeres en altas jerarquías (por ejemplo, las altas sacerdotisas en la religión moche) no representaba ningún problema. Era natural en tanto las mujeres disfrutaban de mayor preeminencia en todos los ámbitos de las sociedades autóctonas, que en las sociedades europeas. Lo anterior solo acrecentaba el desprecio de los conquistadores por las culturas autóctonas americanas.

Algunos párrafos atrás mencionábamos que si bien para Francis Bacon el pecado original, causa de la caída de la humanidad, no podía ser de ninguna manera el que Adam y Eva sostuvieran relaciones sexua$\operatorname{les}^{12}$, tampoco podía ser la búsqueda del conocimiento en sí mismo, lo más importante era el Telos de esta búsqueda ¿Para qué se quiere obtener el conocimiento? Dependiendo de la respuesta, la situación se tornaría buena o mala. Sin embargo, Bacon olvida (muy convenientemente) que quien extendió la mano para tomar el fruto del árbol del conocimiento, fue Eva no Adam. Eva, la madre de la humanidad según La Torá. Según nuevas e interesantes interpretaciones feministas, Eva es la más curiosa, la que codicia y que arriesga

12 Hay que recordar que según el Génesis la primera orden que Yavhé da a Adam y Eva, fue crecer y multiplicarse (Gén, 1:22), para lo cual las relaciones sexuales son imprescindibles. 
todo para conseguir el conocimiento y sí, para ser como Dios. Es por Eva que hemos conseguido (para bien y para mal) saber que a lo largo de la historia de las civilizaciones, la humanidad ha poseído.

Durante miles de años se ha culpado a las mujeres, personalizadas en la figura de Eva, por causar la expulsión de los seres humanos del jardín del Edén, por sacarnos de un estado de tranquila ignorancia y arrojarnos a un violento mar de cosas por descubrir. Bacon lo sabía, desde luego; empero, ignora a propósito el posible nuevo papel de Eva y continúa su reflexión sin tenerla en cuenta más que como el ser que al igual que la Pandora de los Helenos, trajo todos los males y desgracias al mundo, en tanto y en cuanto la naturaleza de la mujer es incontinente e incompatible con la posibilidad de crear, interpretar y guardar conocimientos.

\section{Los límites del conocimiento como cuestión de género}

Nada en este mundo, el mundo de los sentidos dirían los platónicos (y Platón claro), nada es infinito. Ni siquiera el conocimiento lo es. No podemos conocerlo todo, no importa lo que la propaganda de la Modernidad nos haya llevado a creer en algún momento. Sea por la falta de senti$\mathrm{dos}^{13}$, instrumentos o por la simple finitud de la razón humana, no podemos conocerlo todo. El conocimiento tiene límites y una de las labores de la epistemología es preguntar sobre estos límites.

13 En cuanto poseer otros sentidos más que la vista, el oído, el olfato, etc., así como en el mejoramiento de los actuales, nos llevaría como especie a un nuevo mundo por conocer.
Es muy curioso que en algún punto de la Modernidad se haya llegado a creer que el ser humano, una especie con tantas falencias, debilidades físicas y limitaciones cognitivas $^{14}$ pudiera conocerlo todo. Bien, lo cierto es que no podemos, y en esta ocasión Bacon tuvo claridad en ello y lo dejó en sus reflexiones. No nos vamos a detener demasiado en todos los límites del conocimiento para el filósofo inglés, toda vez que esto ha sido estudiado ampliamente en el mundo anglosajón y porque no pretendemos descubrir (por millonésima vez) el agua tibia. Nos centraremos, tal cual es el objetivo de este trabajo académico, en descubrir y demostrar los trazos de colonialismo que pudiera haber en el pensamiento de Bacon.

\section{La mujer y el conocimiento}

Aunque para nosotros el sexo de la persona no es considerado un límite ni una objeción para el proceso de aprendizaje o producción de ciencia, para la misógina sociedad inglesa del Renacimiento sí que lo era: las mujeres no podían ni debían participar en la creación, transmisión y acumulación del saber verdadero como ya hemos explicado en otro lugar ${ }^{15}$. Para Bacon, solamente algunas personas con características muy específicas podrían crear ciencia: ser europeo, estar libre de ídolos, y desde luego, ser varón. Para el Visconde de Saint Albans, las mujeres tenían fundamentalmente tres finalidades o usos:

14 Hay cosas que simplemente no podemos conocer. El aterrorizante indeterminismo de la mecánica cuántica y de la evolución de las especies son los mejores ejemplos.

15 El artículo El Barón de Verulam y el Vulgo, publicado en el número 145 de la Revista de Filosofía de la Universidad de Costa Rica. 
El fin de ambas filosofías debería ser el separar y desechar las especulaciones vanas y todo lo vacuo y conservar y acrecentar la sólida y fructífera suerte de que el conocimiento no venga a ser como una cortesana, solo para el plecer y la vanidad, ni como una esclava, para adquirir y ganar en provecho de su amo, sino como una esposa, para la generación de fruto y solaz... (Bacon, 2014: 1176)

Este extracto del Avance del aprendizaje es sumamente interesante y útil para nuestros propósitos pues se establece una metáfora entre los usos (aunque suene terrible a nuestros oídos) que se le deben dar a la especulación filosófica en función del saber y el papel de las mujeres en la sociedad inglesa y en la mente de Bacon. Dependiendo de cómo se utilice la especulación filosófica (mujer), así serán sus frutos. La mujer solo sirve para producir placer, provecho o hijos legítimos que heredarán las posesiones del marido, pero para nada más. Las mujeres son un vehículo para una finalidad, no una finalidad en sí mismas, un objeto, esencial para la reproducción de la especie, para el placer sexual y para ser explotada.

Muchas personas podrían decir que es lógico que Bacon piense así dada la época a la cual pertenece. Sí, es muy lógico y esperable, pero el problema lo constituye el hecho de que este Lord inglés influyó de forma determinante en este constructo llamado Modernidad, la cual para bien y para mal (más para la segunda que para la primera en lo que respecta a los pueblos colonizados) prácticamente afectó a toda la humanidad en los últimos quinientos veinticinco años. En otras palabras, uno ${ }^{16}$ de los dos padres de la Modernidad nos heredó una epistemología misógina.

Es verdad que la posición misógina que caracterizó a Europa hasta bien entrado el siglo XX (en muchos aspectos sigue siéndolo) no fue invención de los filósofos renacentistas, sino más bien herencia de Atenas y la Roma pagana y cristiana, la que definió la Edad Media cristiana (no así la musulmana); empero, se mantuvo un buen grado de complacencia durante todo ese tiempo.

Durante los períodos de conquista, colonización y colonia moderna propiamente dicha, si de algo se encargaron los europeos con esmero fue de desplazar a las mujeres de su status político y religioso ${ }^{17}$, pues para ellos era una aberración que las mujeres tuvieran otro papel más que el de madre, obediente esposa o religiosa.

La trístemente célebre historia de Sor Juana Inés de la Cruz ilustra muy claramente lo dicho en las líneas anteriores. Una mujer que para poder escapar de la subyugación de un esposo, los peligros del alumbramiento y el yugo de la crianza de los hijos, además de poder dedicarse a su pasión - el estudio- decidió convertirse en religiosa. Pero aún así, fue enjuiciada por dedicarse

16 Decimos a uno de los dos pues a la epistemología racionalista y dualista de Descartes, la doble esencia del ser humano, res extensa y res cógita (lugar de los ingenios) le importa poco el cuerpo. Sea hombre o sea mujer, lo que importa será el ingenio.

17 En muchas de las culturas dominadas por los europeos alrededor del mundo, las mujeres habían ostentado un gran poder político y religioso que muy por lo general estaba unido y conllevaban una buena dosis de saberes en muchos ámbitos. 
a labores que no correspondían a su sexo y género: tratar de crear conocimiento.

Si bien es cierto, sor Juana Inés de la Cruz vivió en una colonia española no inglesa, su caso se yergue como ejemplo de la prohibición que en la Modernidad han tenido las mujeres de acercarse al conocimiento, solo por ser mujeres. Y sin embargo, muy lejos de lo que se podría creer o querer creer, las mujeres europeas y estadounidenses no fueron aceptadas, ni bien vistas (cuando pudieran acceder al mundo del conocimiento institucionalizado) hasta hace muy pocas décadas.

Al desterrar a las mujeres de los ámbitos del conocimiento, la Modernidad consigue mantenerlas al margen de uno de sus tres ejes fundamentales: el conocimiento, con lo cual las tendrán dominadas de una nueva forma para una nueva era. En el mundo moderno, la mujer no era necesariamente la hereje, era más bien la bruja (que no está en femenino por casualidad) que ostentaba conocimientos que no serán los avalados, eran muy misteriosos, muy naturales. Pero ante todo, la mujer será la ignorante. Desde luego, esto también se daba en la antigüedad y en la Edad Media cristiana, el dominio hacia la mujer en el Viejo Mundo es milenios más vieja que la Modernidad. No estamos diciendo que la subyugación de las féminas surgiera en la era moderna, estamos diciendo que se reinventó, se adaptó. El dominio epistémico se da en primer lugar hacia las mujeres, luego hacia los demás.

Durante siglos uno de los grandes límites del conocimiento será una cuestión de género. Si todos los hombres (Xy) europeos y aptos para el conocimiento desaparecieran, por más absurdo que pueda sonar, la producción y acumulación de conocimientos desaparecería. Pongámoslo de la siguiente forma: hoy, hasta donde sabemos, somos los únicos animales que creamos conocimiento. Si toda la humanidad desapareciera, la producción de conocimiento desaparecería.

En este punto, la cuestión pasa de ser puramente epistémica a ontológica pues las únicas mentes capaces de los procesos cognitivos necesarios para los conceptos de la ciencia, solo se dan en los cuerpos de los hombres. Los cuerpos de las mujeres serían completamente incapaces de albergar una mente capacitada para la ciencia. Lo interesante es que por lo menos en los muchos textos estudiados de Francis Bacon, en ningún lugar este toma media línea para siquiera intentar justificar su misógina posición epistémica. Para él, la inferioridad cognitiva de la mujer era completamente natural, autoevidente, como los axiomas aristotélicos.

\section{Conclusiones}

Incluso antes del edicto de Tesalónica del año 380 d.C., el cristianismo ya se perfilaba como una religión intolerante. Desde sus propios inicios expansiva, eso es bien sabido. Empero, después del arriba mencionado edicto, la expansividad y la intolerancia se legalizan propiamente, se institucionalizan y son estas dos características, principalmente aunque no únicamente por supuesto, las que desbordaban en el cruel corazón de la mayoría de los conquistadores europeos. 
Más tarde pensadores y filósofos como Francis Bacon sistematizarán (desde una perspectiva más o menos secular) la expansividad y la intolerancia del cristianismo encriptándolas en las colonialidades del ser, del saber y del poder. Y no es que hicieran falta más torpes intentos por justificar la Conquista con todas sus consecuencias. Ya años atrás (1550- 1551), en la Controversia de Valladolid, el Dr. de Sepúlveda había hecho gala de toda su sevicia; empero, tal y como sabemos, Bacon era inglés y para los nativos de Inglaterra era importante tener una justificación en su propio código.

La inhumanidad con la que los europeos intentaron, con un buen nivel de éxito, de borrar las religiones autóctonas de América, es legendaria y muy bien detallada por Fray Bartolomé de las Casas en su Brevísima relación de la destrucción de las Indias. Está de más hacer incapié en el irrespeto que significa para los individuos y los pueblos, arrebatarles sus creencias religiosas, además de su historia y su cultura, sea con suavidad, o con brutalidad.

De la mano con las cuestiones religiosas y culturales están, desde luego, las cuestiones de género, que tal como ya explicamos, aquí en América en la gran mayoría de las culturas autóctonas, las mujeres contaban con más derechos, consideración y prestigio social del que tenían las mujeres europeas en esa época. Tal fenómeno llevó a los conquistadores a ver a los pueblos autóctonos como inferiores y por ello más necesitados de "civilización". Después de todo, ¿qué se podía esperar de pueblos donde las mujeres podían decidir solas y en ocasiones mandar a los hombres? La misoginia de los europeos se encargó de eliminar esa "aberración" y nos contaminó hasta el día de hoy. Muy pocos saben cuál es el origen de la misoginia que está detrás de toda la violencia hacia las mujeres. Algunos eurocentricos dicen que "la misoginia viene de los indios", no se pueden creer que algo malo venga de Europa, pero sí que han venido y siguen viniendo cosas malas desde Europa, y mientras no tomemos conciencia de lo que hicieron los europeos, de lo que siguen haciendo, nunca podremos salir del hoyo en que nos metieron hace ya más de 500 años.

\section{Referencias}

Bacon, F. (1988). Avance del Aprendizaje. Madrid: Alianza editorial. Versión Kindle. (2009). Novum Organon. Madrid: Trotta. . (2014). Dignitate et Augmentis Scientiarum. Ohio: Minerva Classic. Versión Kindle. (2014). The Great Instauration. Ohio: Minerva Classic. Versión Kindle.

(2014). Preparative Toward a Natural and Experimental History. Ohio: Minerva Classic. Versión Kindle. . (2014). Valerius terminus: of the Interpretatio of Nature. Ohio: Minerva Classic. Versión Kindle.

Descartes, R. (1986). Discurso del método. Madrid: Alianza Editorial.

Dussel, E. (1992).1492. El encubrimiento del otro. Hacia el origen del mito de la modernidad. Madrid: Nueva Utopía. 
. (2005). Europa, modernidad y eurocentrismo. En Edgardo Lander (comp.). La colonialidad del saber: eurocentrismo y ciencias sociales. Perspectivas Latinoamericanas. Buenos Aires: Clacso.

Grosfoguel (comps.). El giro decolonial. Reflexiones para una diversidad epistémica más allá del capitalismo global. Bogotá: Universidad Javeriana-Instituto Pensar, Universidad CentralIESCO, Siglo del Hombre Editores.

Herrera, B. (2007). Las dos caras de la moneda: modernidad colonial y metropolitana. Pasos. San José: DEI.

Mignolo, D. W. (2002). Historias locales/ diseños globales. Colonialidad, conocimientos subalternos y pensamiento fronterizo. (Prefacio). México: Akal Ediciones. . (2005). La colonialidad a lo largo y a lo ancho: el hemisferio occidental en el horizonte colonial de la modernidad. En Edgardo Lander (comp.). La colonialidad del saber: eurocentrismo y ciencias sociales. Perspectivas Latinoamericanas. Buenos Aires: Clacso.
(2007). El pensamiento decolonial: desprendimiento $y$ apertura. En Santiago Castro-Gómez y Ramón Grosfoguel (comps.). El giro decolonial. Reflexiones para una diversidad epistémica más allá del capitalismo global. Bogotá: Universidad Javeriana-Instituto Pensar, Universidad Central-IESCO, Siglo del Hombre Editores.

Quijano, A. (1989). Modernidad, identidad y utopía en América Latina. Quito: Ediciones El Conejo. . (2005). Colonialidad del poder, eurocentrismo y América Latina. En Edgardo Lander (comp.). La colonialidad del saber: eurocentrismo y ciencias sociales. Perspectivas Latinoamericanas. Buenos Aires: Clacso.

(2007). "Colonialidad del poder y clasificación social". En Santiago Castro-Gómez y Ramón Grosfoguel (comps.). El giro decolonial. Reflexiones para una diversidad epistémica más allá del capitalismo global. Bogotá: Universidad Javeriana-Instituto Pensar, Universidad Central-IESCO, Siglo del Hombre Editores. 
